\title{
The Innovation of Retail Banks in the Cross-Border Payment Fund Transfer System: Take OCBC as an Example
}

\author{
Shuyu Ye1, Yingjing Zhu2 ${ }^{2 *}$ Erzhuo Lu$^{2 *}$ \\ ${ }^{1}$ School of Economics and Commerce, South China University of Technology, Guangzhou, China \\ ${ }^{2}$ Business School, University of Birmingham, Birmingham, UK \\ Email:sukiyip007@gmail.com,yxz775@student.bham.ac.uk, ex1730@student.bham.ac.uk
}

How to cite this paper: Ye, S.Y., Zhu, Y.J. and Lu, E.Z. (2019) The Innovation of Retail Banks in the Cross-Border Payment Fund Transfer System: Take OCBC as an Example. Modern Economy, 10, 1479-1486. https://doi.org/10.4236/me.2019.105098

Received: April 7, 2019

Accepted: May 27, 2019

Published: May 30, 2019

Copyright (อ 2019 by author(s) and Scientific Research Publishing Inc. This work is licensed under the Creative Commons Attribution-NonCommercial International License (CC BY-NC 4.0). http://creativecommons.org/licenses/by-nc/4.0/ (c) (i) (8) Open Access

\begin{abstract}
This article takes Singapore Oversea-Chinese Banking Corporation as an example to illustrate the radical reform brought by the blockchain network in the bank payment system. By comparing the traditional payment forms with that under the blockchain network, this paper expounds that the blockchain-based cross-border payment fund transfer system is securer, more transparent and reliable, as well as more efficient. It also discusses the open legal environment in Singapore that promotes the practice of blockchain in the banking industry. However, the establishment and maintenance of the blockchain network are costly, and the banks using blockchain technology are exposed to potential loopholes in the network.
\end{abstract}

\section{Keywords}

Blockchain, Cross-Border Payment, Retail Banks

\section{Introduction}

With the advent of the era of big data, the world develops into progressively more digitalized [1]. Research by Yoo suggests that the nature of products and services is being revolutionized by the widespread application and innovation of digital technologies [2]. As Deloitte points out, especially in the banking sector, copious numbers of traditional banks start to promote a greater payment experience through innovation, by which they can significantly enhance their market competitiveness [3]. For example, the blockchain, a distributed databank to record transactions that can be shared among different groups, has been used by

*Yingjing Zhu and Erzhuo Lu are juxtaposed as second author. 
several advanced banks to improve business practices according to Crosby [4]. Overall, this essay has chosen Oversea-Chinese Banking Corporation as an example and demonstrated how it improved its cross-border payment system through blockchain, the typical regulatory environment that supported its application and some drawbacks it may encounter.

\section{Who Is Oversea-Chinese Banking Corporation and What Has It Done?}

Oversea-Chinese Banking Corporation (hereinafter referred to as OCBC), the second largest financial service company in Southeast Asia, is the most long-standing bank founded in 1932 by a merger of three local banks in Singapore [5]. On 14 November 2016, Singapore OCBC became the first one to complete cross-border payments in Southeast Asia by using the blockchain technology [6]. The typical application of blockchain of OCBC is the cross-border payment fund transfer system as reported by Fintechnews Singapore [7]. In an article by Cabral, Dierick and Vesala, traditionally, ОСВC's cross-border payments refer to transactions involving individuals, companies, banks or settlement agencies operating in at least two different countries by SWIFT under the MEPS+ (Malaysia Electronic Payment System) [8]. However, with the application of blockchain, the trading banks can communicate and make transactions directly through the blockchain platform rather than payment intermediaries (Figure 1). This decentralized form of transaction, as MrMohanty (CFO of Singapore Monetary Authority (MAS)) said, has brought a revolutionary change in banking services and injected vivacity in banking sectors [9].

\section{What Benefits Does OCBC Get by Applying Blockchain?}

The blockchain provides a much securer environment to OCBC's cross-border payment. Nowadays, with technology advances, numerous transactions are conducted through the internet, which can increase the possibility of privacy disclosure and cyber attacks. According to ABC News [10], approximately 50

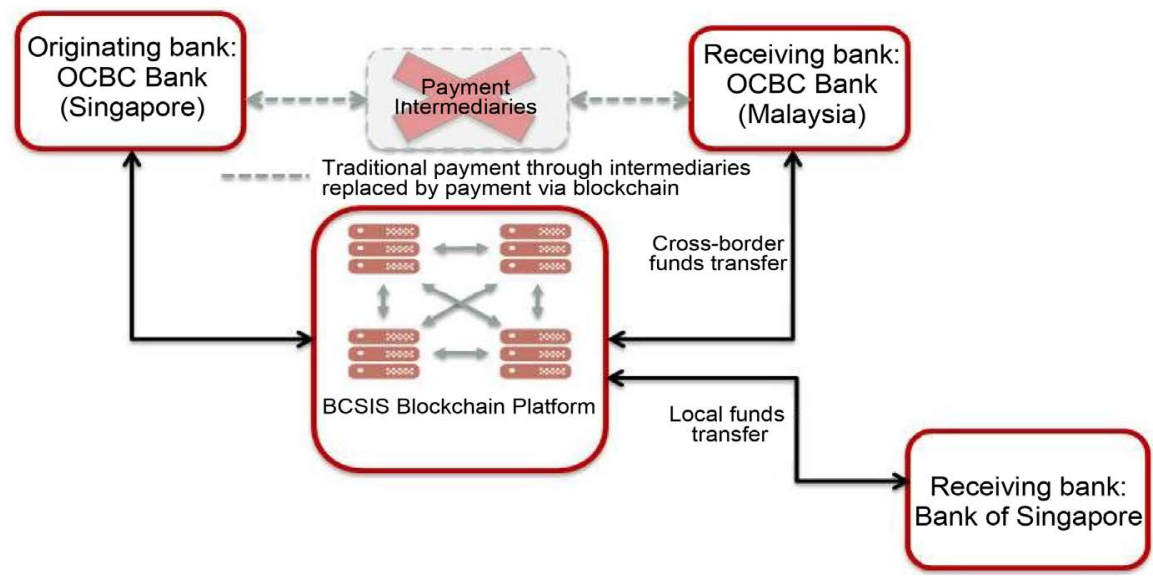

Figure 1. Cross-border fund transfers in OCBC using blockchain solution (Source: OCBC, 2016). 
million Facebook users were attacked for security breaches in 2018, as a consequence of which Facebook's share price fall sharply. Blockchain, a more reliable and securer network system, can exactly protect OCBC from these potential risks. Firstly, the authenticity of transaction records among banks can be guaranteed. Under the blockchain system, Xu, M.X., Tian, Y. and Li, J.Y report that the occurred transactions cannot be proved to be authentic unless over $50 \%$ of the nodes' data are consistent with them [11]. This feature also guarantees the irreversibility of transaction records since it is nearly impossible to change over half of the node's data at the same time.

Secondly, OCBC's transactions records can be permanently reserved [11]. Based on blockchain, current transactions records are securely encrypted and bound sequentially into a chain with all previous records (Figure 2), and thus nearly all transaction information is traceable. According to Zhang [1], Coin Check, a virtual currency exchange, was protected by blockchain from losing a peer-to-peer cryptocurrency worth about $\$ 500$ million after being hacked in 2018, because the thieves could not accept the COINS in wallets since those COINS were tracked to every account and wallet in the blockchain network. Apart from the cross-border system, the work of Tapscott shows that the securer feature of blockchain also brings great benefits to financial assets such as bonds and stock contracts, and some intricate services of OCBC like credit certification, savings and loans [12]. Thus, the application of blockchain allows OCBC to transact in a more reliable, secure and solid environment.

Additionally, the application of blockchain into the cross-border transaction makes the process faster and cheaper. This mainly attributes to the decentralized form of payment according to Deloitte [13]. Under the original MEPS+ cross-border payment system in OCBC, MAS points out that there are several settlement intermediaries involving that serve as guarantee agencies to prevent forge and tamper in materials, which are always blamed for high cost and low efficiency [14]. However, after introducing blockchain into the payment system, research by Yang and Chen states that these potential problems of fraud and tamper are solved by distributed ledger technology, and thus the transaction process can be greatly simplified by removing most of the intermediaries [15]. Besides, it can directly involve trading parties and achieve point-to-point transmission, which dramatically shortens the transaction time and lowers the cost [1]. The OCBC simplified process of transferring money under the blockchain payment system is shown in Figure 3. This new system is developed based on the original MEPS+ (Malaysia Electronic Payment System). When OCBC in different countries, say Bank A and B, need to conduct remittance, they first transfer

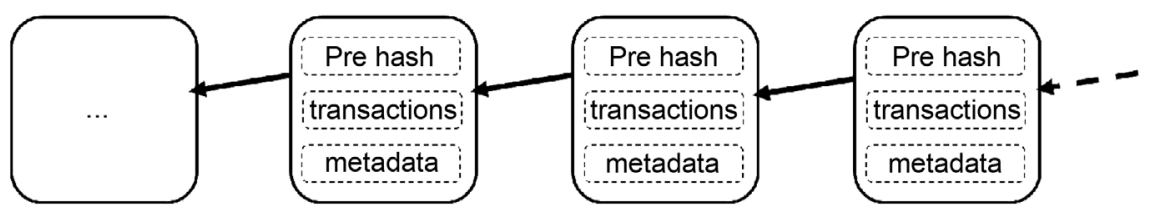

Figure 2. Blockchain structure (Source: Yang and Chen, 2017). 


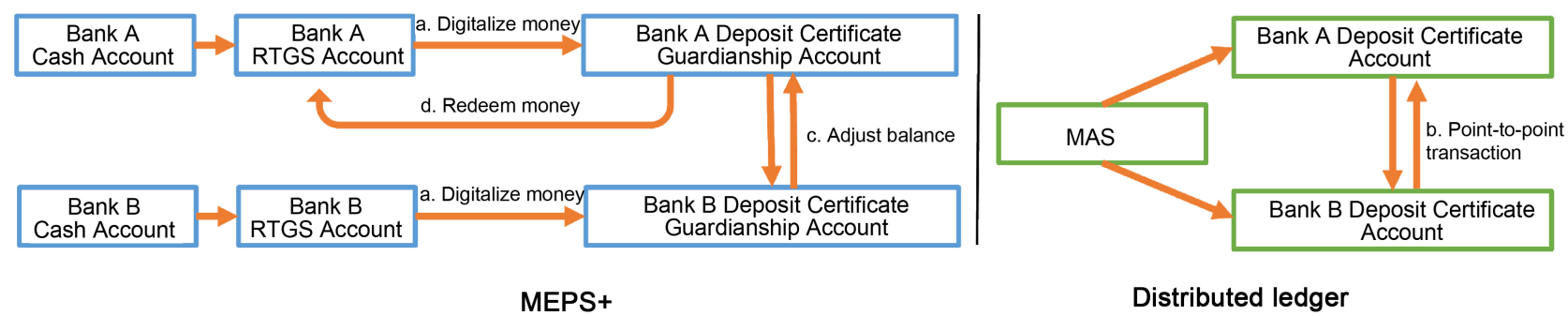

Figure 3. OCBC simplified cross-border payment system under blockchain (Source: own presentation and Deloitte, 2017).

the amount of money into the RTGS (Real Time Gross Settlement) Accounts from their Cash Accounts. Then, they purchase deposit certificates from MEPS+ and after that MEPS+ transfer the required value of the deposit certificate from banks' RTGS Accounts to the Deposit Certificate Guardianship Accounts. In this step, real money is transformed into digital money. Next, MAS distributes the equivalent deposit certificate to the bank's account in the distributed ledger side. Since MEPS+ and distributed ledger are two independent ledgers, there is synchronization between them rather than a transfer of funds. Thus, the amount of money in banks' Deposit Certificate Guardianship Accounts is not changed during this process. Now, banks can conduct remittance in the distributed ledger with deposit certificates.

When the transfer of funds finishes, the balance of the Deposit Certificate Guardianship Account is adjusted according to the Deposit Certificate Account. Ultimately, banks redeem their money from their Deposit Certificate Guardianship Account back to the real money. Since the transaction made under the distributed ledger relies on network system without manual operation in intermediaries, this new transaction process can run on 7/24 as pointed out by Deloitte, which is faster and more efficient compared to the MEPS+ [13]. According to OCBC news [6], based on blockchain, money transfers between OCBC banks in Singapore and Malaysia take even less than five minutes to complete. Moreover, it is predicted by Ngai (Figure 4) that there will be a dramatic drop in cost by over ten dollars each transaction after the application of blockchain in the cross-border payment system from approximately $\$ 26$ to $\$ 15$, of which about $\$ 8$ is paid to intermediaries which used to help with the bookkeeping, transaction records and balance reconciliation. The remaining $\$ 3$ is compliant, including network maintenance costs, bug investigations, and foreign exchange costs [16]. Therefore, it is very likely that OCBC can save a large number of transaction fees and hence become more competitive in the market.

\section{What Is the Regulatory Environment That Supports OCBC's Application of Blockchain?}

Reference to Peters, G.W., Panayi, E. and Chapelle, A. reveals that financial innovation is often ahead of regulation, so blockchain as new technology has risks and needs to be improved to promote its development [17]. The European Central Bank now has no clear legal rules to restrict blockchain, and some of New 


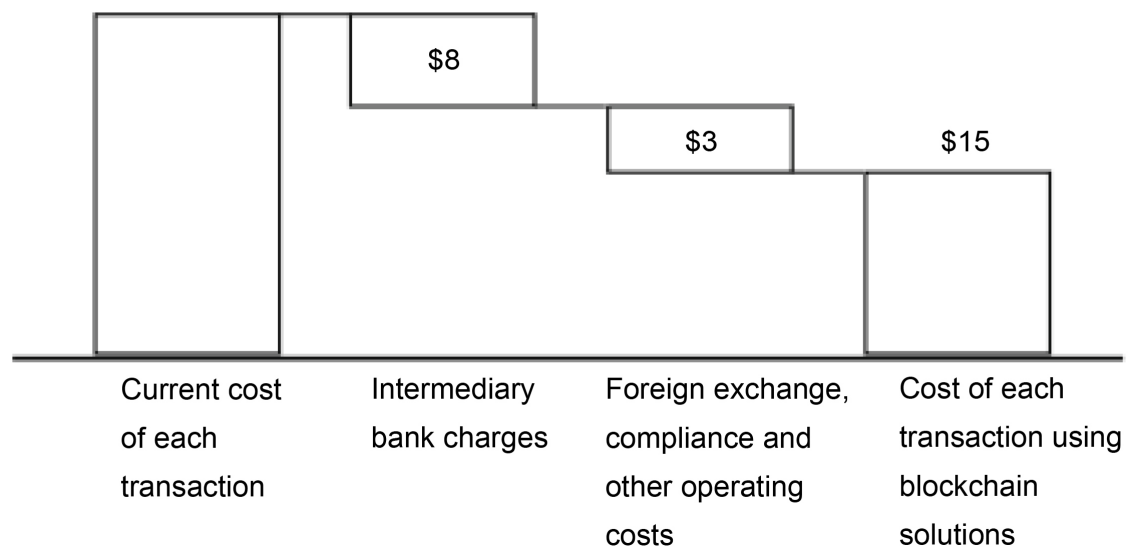

Figure 4. Application of blockchain in cross-border payments (Source: Ngai, J.L. (2016), cited in Guo and Liang, 2016).

York's overly strict policies have caused most companies to suspend blockchain business, which they believe will create a compliance burden. However, according to Asia Blockchain Review, officials from MAS said in an interview with Bloomberg that MAS, as Singapore's central bank and financial regulator, will maintain an "open mind" with no plans to regulate cryptocurrencies and the regulations do not supervise the electronic money itself but have the supervision of intermediaries [18]. That is, as indicated by Wall J., the Singapore government promotes the development of blockchain with an open mind [19]. Based on the preferential blockchain regulations, Singapore is expected to become the hub of the Asian blockchain as a policy to foster the local development of blockchains. In recent years, Singapore has proved to be a force that cannot be ignored in this field. Currently, it has about 400 financial technology companies and welcomes more than 20 global financial institutions to set up innovative laboratories to test new ideas [18]. This open regulatory environment exactly supports OCBC to apply blockchain in its services. Moreover, Lim and Randhawa make clear that the political and social stability, as well as sound macroeconomic fundamentals and policies in Singapore also support its application of blockchain [20].

\section{What Drawbacks Can OCBC Encounter?}

Nevertheless, there are also some disadvantages for OCBC when applying blockchain. Firstly, it can be difficult for OCBC to transfer money via blockchain-based payment system to those traditional financial institutions who have not participated in the blockchain network. According to Bahl, since the application of blockchain in real business requires a strong IT foundation, currently, only a limited number of banks can implement the blockchain technology into the existing business operation [21]. This can prevent OCBC from maximizing the utility of blockchain in the payment system to a large extent. However, the increasing application of blockchain technology of OCBC together with other banks can put pressure on traditional financial institutions to reform the opera- 
tion of remittance and other businesses, driving the whole banking sector into a more simplified, advanced and efficient working environment.

Secondly, the uncertainty about this new technology might get OCBC into potential risks. In an article by Lin and Liao, with the consensus mechanism of blockchain, once the miners hold $51 \%$ computing power by cooperating and forming "mining pools", they can take control this blockchain, modifying the transaction data and stopping the transaction verification [22]. The exposure of this potential loophole can significantly damage OCBC's reputation for keeping information. However, with the increasing block reward, fewer and fewer miners have incentives to join together and risk controlling the blockchain. Meanwhile, according to The Economist, it is particularly difficult to create a supercomputer which has a strong computing power only used to attack one database [23]. For the sake of safety, strict regulations of information management towards blockchain are urgently needed as stated by Shearman \& Sterling, R3, and BAFT [24]. Thirdly, the application of blockchain might threaten the whole retail banking sector including OCBC in the long term. This is because the achievement of a point-to-point transaction under blockchain might ultimately eliminate the transaction intermediaries of retail banks, which can be more attractive for consumers due to the much lower fees.

\section{Conclusions}

In conclusion, this essay discussed the benefits that OCBC can get from the blockchain-based cross-border payment service, which is securer, faster, cheaper and more transparent. It enables OCBC to achieve higher quality services and more optimal cost-effectiveness, and thereby capture more customers and gain a greater market share. These are the reasons why OCBC choose to apply the blockchain in its services. However, the blockchain system is not perfect. It is possible to be exploited by someone with concealed intentions, and the potential risk of information tampering and transactions disruption can get OCBC into trouble. Additionally, due to the nature of blockchain, banks like OCBC may not play an essential role as they do today. Hopefully, in the future, under a deliberate and open regulatory environment in Singapore, OCBC will make better use of the blockchain and strike a balance with the development of technology.

However, this study has potential limitations. The benefits of utilizing blockchain illustrated are mainly based on recent data and literature research. Nevertheless, the availability and the time period of data are limited. Our result about the quantitative benefit may be vague, as 1) the advantages brought by the faster speed of cross-border payment system and securer payment environment are difficult to be quantified; 2) there are lacking long-term financial data from OCBC to clearly show the gross profits due to the lower transaction expenses; 3 ) research about the operation of blockchain-based cross-border payment system and legal environment in other countries, which are different from Singapore's, is insufficient to refer to and thus the extensibility of conclusion in other parts of 
the world needs to be concerned. Nevertheless, the qualitative analysis of the merits and shortcomings of applying blockchain in banks' cross-border payment system is able to support the result. What the future research in this filed can improve is to extract the specific data of banks' profits and cost in operating such payment system and use an appropriate model to quantify the benefits of time-saving so as to test the accurate benefits that the blockchain technology can have. In addition, more potential and unknown risks arisen from the usage of blockchain need to be researched.

\section{Conflicts of Interest}

The authors declare no conflicts of interest regarding the publication of this paper.

\section{References}

[1] Zhang, W. (2018) How Can Blockchain Improve the IT Security Ecosystem? https://www.credit-suisse.com/ch/en/articles/asset-management/how-can-blockchai n-improve-it-security-201804.html

[2] Yoo, Y., Boland, R., Lyytinen, K. and Majchrzak, A. (2009) Organizing for Innovation in the Digitized World. Organization Science, 20, 278-279. https://doi.org/10.1287/orsc.1080.0416

[3] Deloitte Access Economics (2014) Competition in Retail Banking. https://www2.deloitte.com/content/dam/Deloitte/au/Documents/Economics/deloitt e-au-economics-retail-banking-competition-010314.pdf

[4] Crosby, M., Pattanayak, P., Verma, S. and Kalyanaraman, V. (2016) Blockchain Technology: Beyond Bitcoin. Applied Innovation Review, No. 2, 71.

[5] OCBC Group (no date) Overviews. https://www.ocbc.com/group/who-we-are/group-business.html

[6] OCBC Group (2017) OCBC Bank, HSBC and MUFG, Together with the Infocomm Media Development Authority, Complete Proof-of-Concept on ASEAN's First Industry Know Your Customer Blockchain.

https://www.ocbc.com/group/media/release/2017/ocbc-hsbc-mufg-kyc-blockchain. $\underline{\mathrm{html}}$

[7] Fintechnews Singapore (2016) First Bank in SouthEast Asia to Use Blockchain Technology for Payment Services.

http://fintechnews.sg/6726/blockchain/first-bank-southeast-asia-use-blockchain-tec hnology-payment-services

[8] Cabral, I., Dierick, F. and Vesala, J. (2002) Banking Integration in the Euro Area. https://www.ecb.europa.eu/pub/pdf/scpops/ecbocp6.pdf?5d8094d0f17c4870248c403 $\underline{1 \mathrm{c} 3889 \mathrm{bfd}}$

[9] OCBC Group (2016) OCBC Bank Is First Bank in SEA to Use Blockchain Technology for Cross-Border Payment Services. https://www.ocbc.com/group/media/release/2016/blockchain-technology.html

[10] ABC News (2018) Facebook Cyber-Attack Sees Data Stolen from 29 Million Accounts in Its Largest Ever Data Theft.

https://www.abc.net.au/news/2018-10-13/facebook-hack-saw-data-stolen-from-29$\underline{\text { million-accounts/10373030 }}$ 
[11] Xu, M.X., Tian, Y. and Li, J.Y. (2017) Picture Presentation of Blockchain. Zhongxin Press, Beijing.

[12] Tapscott, D. and Tapscott, A. (2016) How Will Blockchain Change Banking? How Won't It?

https://www.huffingtonpost.com/don-tapscott/how-will-blockchain-chang_b_9998 348.html

[13] Deloitte (2017) Project Ubin: SGD on Distributed Ledger. http://www.mas.gov.sg/ /media/ProjectUbin/Project\%20Ubin\%20\%20SGD\%20on \%20Distributed\%20Ledger.pdf

[14] MAS Group (2016) MAS Electronic Payment System (MEPS+). http://www.mas.gov.sg/singapore-financial-centre/payment-and-settlement-system s/clearing-and-settlement-systems/meps.aspx

[15] Yang, B.H. and Chen, C. (2017) Principle, Design and Application of Blockchain. China Machine Press, Beijing.

[16] Guo, Y. and Liang, C. (2016) Blockchain Application and Outlook in the Banking Industry. Financial Innovation, 2, 24. https://doi.org/10.1186/s40854-016-0034-9

[17] Peters, G.W., Panayi, E. and Chapelle, A. (2015) Trends in Cryptocurrencies and Blockchain Technologies: A Monetary Theory and Regulation Perspective. The Journal of Financial Perspectives, 3, 92-113. https://doi.org/10.2139/ssrn.2646618

[18] Asia Blockchain Review (2018) Singapore Blockchain Regulations and Landscape. https://www.asiablockchainreview.com/singapore-blockchain-regulations-and-land scape

[19] Wall, J. (2018) Singapore Introduces Regulatory Framework for Crypto Payment Services.

https://www.investinblockchain.com/singapore-crypto-payments-regulatory-frame work

[20] Lim, G.H. and Randhawa, S.D. (2005) Competition, Liberalization and Efficiency: Evidence from a Two-Stage Banking Model on Banks in Hong Kong and Singapore. Managerial Finance, 31, 52-77. https://doi.org/10.1108/03074350510769479

[21] Bahl, M. (2017) The Future of Blockchain in Asia-Pacific. https://www.cognizant.com/whitepapers/the-future-of-blockchain-in-asia-pacific-c odex3240.pdf

[22] Lin, C.I. and Liao, C.T. (2017) A Survey of Blockchain Security Issues and Challenges. International Journal of Network Security, 19, 653-659.

[23] The Economist (2014) Losing to Win. https://www.economist.com/schumpeter/2014/06/23/losing-to-win

[24] Shearman \& Sterling, R3, and BAFT (2018) Code Is Not Law: The Legal Background for Trade Finance Using Blockchain. https://www.r3.com/wp-content/uploads/2018/09/Code_Is_Not_Law_R3.pdf 